as well as the need for and importance of research. You can read it online at the CCQ web site (http://catalogingandclassificationquarterly.com/ccq47nr8.html\#editorial)

What does this mean for you? Ms. Carlyle suggests several ways that all of us can participate in this endeavor:

- Generate and share inspiring research ideas;

- Do your own research;

- Present and publish your research;

- Encourage and support others doing research (fill out those email surveys);

- Read research papers and articles on bibliographic control;

- Organize a research program or other event on bibliographic control at a conference you attend;

- Spread the word-let everyone interested in cataloging, catalogs, metadata, bibliographic control of any sort know about it;

- Attend programs on cataloging research at ALA and other conferences.

\title{
LIBRARY OF CONGRESS PUBLICATIONS AVAILABLE
}

On the Record Report Recommendations the Library of Congress Should Pursue

Over the Next Four Years: Report to the Associate Librarian for Library Services. (PDF, dated September 15, 2009, http://www.loc.gov/bibliographicfuture/news/OTR rep response final 091509.pdf) This report was prepared by the OTR Report Implementation Working Group, co-chaired by Regina Reynolds and Bruce Knarr. It is a planning document detailing the projects, contingent projects, and areas of investigation recommended for action by LC over the next four years.

Library of Congress Study of the North American MARC Records Marketplace. (PDF, dated October 2009, http://www.loc.gov/bibliographic-future/news/MARC Record Marketplace 2009_ 10.pdf) This study was prepared by Ruth Fischer and Rick Lugg of R2 Consulting LLC. This forty-seven page study analyzes the results of surveys in order to assess the current patterns of creation and distribution of MARC records in the U.S. and Canada with regard to economic factors, sufficiency and redundancy of production, and incentives and barriers to production.

\section{SELECTED ARTICLES FROM CURRENT LIBRARY JOURNALS}

Baca, Murtha, and Elizabeth O'Keefe. "Sharing Standards and Expertise in the Early 21st Century: Moving Toward a Collaborative, 'Cross-Community' Model for Metadata Creation." International Cataloguing and Bibliographic Control 38, no. 4 (October/December 2009): 59-67. 